\title{
Research on Teaching Evaluation System Based on Project Teaching Method
}

\author{
Yulong Zuo \\ Primary Education Academy \\ Linyi University \\ Linyi, China
}

\begin{abstract}
Project teaching method is a learning method that absorbs the essences of three teaching methods namely inquiry teaching method, task driven teaching method and case teaching method and integrates the knowledge and skills for special posts, to ultimately achieve students' knowledge generation and capability development through active learning and independent knowledge building in the process of task completion, and further to find a learning way in practice. Traditional teaching evaluation method has been unable to meet the needs of the project learning. In order to evaluate and improve the project teaching effect and make an incentive and instruction for its following project teaching, this paper analyzes the necessity of building a project teaching evaluation system and proposes a principle of diversification, development and objectivity that the project teaching evaluation should follow, and further builds an evaluation system feasible for the project teaching.
\end{abstract}

Keywords—project teaching; evaluation system; project works; project learning

\section{INTRODUCTION}

Project teaching method, also called project teaching or project based learning, refers to a teaching activity where teachers work together with students to carry out a complete project, aiming to well integrate the curriculum theory and practice in teaching so improve students' comprehensive capabilities of solving practical problems through fully exploring the students' senses of innovation and teamwork skills. At present, there are many colleges and universities especially higher vocational colleges, which have recognized the necessity of the project teaching, besides, it has been widely used more and more fields, it has been not only used in courses of science and engineering such as computer operation, mechanical manufacturing, and but also in an attempt in many courses of liberal arts. With multiple evaluation methods adopted and the principle of objectivity and development followed in the project teaching, this article aims to build a complete system for the project teaching evaluation and make it better used in the future teaching.

\section{The NeCESSity Of BuILding A Project Teaching EVALUATION SYSTEM}

\section{A. Traditional Evaluation Methods Have Been Unable to} Meet Characteristics of Project Teaching Team Works

It is a little difficult to define individual performances within the project teaching team works. At present, in the practice of computer-based course project teaching, it is found that individual performances are very difficult to confirm with a lot of teamwork works. The evaluation on the team mainly depends on the completion of the team as a whole, and the team members will bear responsibilities and shared achievements altogether, during the production of the team works, there is no whole-course monitoring by teachers, so it is uneasy to make a visual judgment on what and how the team members contribute. For instance, one or two members in some teams are always depended on to complete the task of the team but others have no chances for or have not participated in the work, after one or two excellent students spend a lot of time completing a project or task, their scores are not higher compared to those completed by all team members, this result will not only hit the self-confidences of those who work hard and diligently but also further the dependency of some others. Therefore, after the students have completed the teamwork works in the project teaching, we have to choose an appropriate evaluation method to confirm the teamwork performance and the individual one in order to make it fair and efficient.

\section{B. Necessity to Promote Students' Initiatives}

If students' teamwork works are evaluated simply according to traditional course evaluation method, there will be defects whether it is evaluated by teachers separately or by students. And disguised cooperation should be prevented for and between teams in the project teaching, for instance, some students who are highly skilled act as "saviors" in a task, yet some hide themselves in the honors of of workmates, having nothing to do and muddling along, which have been completely contrary to the original intention that teamwork is supported to cultivate students' consciousness and abilities in cooperation, as a result, the project teaching effect is greatly reduced. Some students fail to acquire the essences of teamwork via the teamwork tasks, instead they are possibly stimulated in laziness, and dependence. In order to improve the 
students' enthusiasm, during the evaluation, we shall value the evaluation not only on students "finished products", but also on their "semi-finished products", not only on excellent products, but also on low-quality products. In a word, the evaluation method should be kept flexible and personalized, it shall consider the students' history, value their current conditions and also focus on their future, and the evaluation shall involve not only knowledge, skills, learning process and methods, but also emotions, attitudes and philosophies.

\section{Necessity to Improve Students' Self Identity}

The college stage is a key process where students have their philosophies formed and it is also a sensitive period for students to set self confidence and self-identity. So the evaluation shall help in favor of the development and formation of students' personal cultivation and scientific literacy. During the evaluation, it shall consider the students' history, value their current conditions and also focus on their future, and the evaluation shall be kept diverse and comprehensive, it shall involve not only knowledge, skills, but also emotions, attitudes and philosophies, learning process and methods, etc. In the meantime, others' evaluation shall be combined with self evaluation so as to help students to recognize themselves, change themselves and set self confidences.

\section{Necessary to Stimulate and Guide Teachers and Students}

With the project teaching used, on the evaluation on the teaching effect is a key link for the project teaching, the evaluation is a reflection of students' learning result in previous stage and also provides an important reference for follow-up teaching by teachers. The evaluation given here includes teachers' evaluation on students, students' evaluation on workmates, students' evaluation on teachers, as well as teachers and students' evaluation on the project, etc. Since the evaluation conclusion may generally bring a direct influence to the image and honor and benefit of the objects concerned, the evaluation often stimulate the objects' motivation for achievements, driving them in pursuit of favorable evaluation results and encouraging them to make full efforts for work so as to create a bigger project learning. Besides, the evaluation will also promote teachers to reflect in the teaching process, improve the defects there, and make the project rational to set, and it will be a great promotion for the follow-up teaching effect of teachers.

\section{EVAluAtion PRINCIPLES For The ProJeCt TEACHING}

\section{A. Diversification Principle}

The works of student team in a certain teaching project should be evaluated roundly. The relation between teachers and students is equal and harmonious. The evaluation should not be confined to teachers' evaluation on students. It includes the evaluation of students in the team, students' evaluations on teachers and the evaluations of teachers and students for the project setting, in order to achieve the diversification of evaluation. [2] We should fully arouse students' enthusiasm in the evaluation. Moreover, the evaluation criterion should also be diversified. Different evaluation criterions should be formulated for the different courses and the works of teams in different projects of the same course. It requires the diversification of evaluation indexes and specific items. The evaluation criterions and indexes should be adjusted in line with different projects.

\section{B. Development Principle}

The team development and students' personal development should be evolutionary. We should pay attention to the development evaluation. Because the project teaching for students is at the primary stage, it is allowable if the quality of works of the team is not high for the inadequate experience. We should believe they will greatly improve after many times of practice. Therefore, the development principle should be considered in the evaluation of project teaching, to know about students' whole learning process, develop and find students' potentials through communication with them as well as roundly evaluate students through the developmental perspective and dynamic methods, observing changes of their cognition, emotion, attitude, values, teamwork ability, innovation and practical ability.

\section{Objectivity Principle}

The objectivity principle means teachers must follow the objective facts instead of mixing personal emotions in evaluating works of the team. Teachers' evaluation on students is often unfair because of the personal emotions. Students are sensitive to the objectivity of evaluation so it will directly influence students' enthusiasm in the follow-up study and the effects of the follow-up project teaching. It requires teachers to consider the physical truth of teaching projects and the physical condition for students to complete the works in the evaluation, such as the team size, teacher's guidance and students' personality differences, so as to correctly and roundly reflect the quality of students' works and their contributions for the team. The objective evaluation can strengthen the confidence of the team and individuals as well as stimulate their enthusiasm in learning.

\section{The Principle of Formative Evaluation Combining with Summative Evaluation}

The teaching evaluation must run through the project teaching. As an important link of the project teaching, it relates to the formation of democratic and equal teaching atmosphere, students' personality development and the formation of outlook on life and the world. Teachers should pay attention to students' learning results and development through diversified and multi-angle evaluation ways; focus on the understanding and grasp of students' knowledge and skills as well as the formation and development of their emotions and attitudes; carry out horizontal comparison between students, respect their differences and attach importance to the vertical comparison between students' past and present, learning situations before, in and after class.

The formative evaluation and the traditional summative evaluation in the project teaching are relative. The formative evaluation means evaluating the underway teaching activities to adjust the teaching process and ensure the realization of teaching objectives. The evaluation on students' performance 
in daily life and the development in emotion, attitude and strategy is the development evaluation through continuous observation, record and reflection on students' learning process, so as to stimulate students' learning, help them to effectively control the learning process and get a sense of accomplishment, strengthen their confidence and train the team spirit, letting students change from passive recipients to the main body of evaluation and the active participants. The summative evaluation means evaluating the final results of teaching activities to provide teaching basis for decisionmaking or resolution. In the project teaching, it is necessary to integrate the formative evaluation with the summative evaluation to evaluate students scientifically.

\section{The Methods To Evaluate The Project Teaching}

\section{A. Evaluation on the Works of Student Team}

We adopt the joint evaluation method of teachers and students, namely the teachers and students evaluate works of the team jointly. The score is given by teachers and students. In order to ensure the objectivity of evaluation, in teacher evaluation, one work can be graded by two teachers of the course and get the average score $(\mathrm{T})$; in student evaluation, one team grades the works of other teams and get the average score (S). Thus the score of work from a team is $(\mathrm{Z})$ :

\section{$\mathrm{Z}=\mathrm{T} \times 60 \%+\mathrm{S} \times 40 \%$}

In the implementation of specific projects, we can adjust the weight coefficient. In the mutual evaluation, selfevaluation can be replaced by the evaluation given by other teams. The scores given by a team must involve the scores given by all the team members. The evaluation on works of other teams can train students' sense of responsibility and critical thinking. Although the evaluation is a little complicated, it is very necessary.

\section{B. Evaluation on Team Members}

Here we combine the team evaluation with the evaluation of team members to exert the initiative of students. The teacher only monitors the evaluation process instead of participating in the evaluation directly. The evaluation score of team members consists of two parts, one is the score $(\mathrm{Z})$ of works of the team, the other is the average score $(\mathrm{P})$ given by the team members. It helps the interaction between team members, trains students' sense of group honor and teamwork spirit and then improves the cohesion of learning team. Therefore, in completing the works, the team leader must record the tasks fulfilled by members in detail, the quality and their attitudes. In order to ensure the evaluation is objective, each member must provide basis in grading. Because in the implementation of project, the role of team leader is different from that of the common team members, we separately list the score given by the team leader and endow certain weight number, setting the score given by the team leader as $(\mathrm{C})$. Thus we can get the score $(\mathrm{H})$ of team member:

\section{$\mathrm{H}=\mathrm{Z} \times 30 \%+\mathrm{C} \times 20 \%+\mathrm{P} \times 50 \%$}

The weight number changes dynamically according to specific circumstances. The diversified evaluation mechanism requires the team members must have a sense of responsibility, [3] which effectively strengthen their sense of group honor.

\section{Combine the Process Evaluation with the Outcome Evaluation}

The evaluation aims at checking the teaching effects. It covers the project works completed by students and the project-oriented learning process of students, including students' ability in independent study and cooperative learning, communicative competence, learning attitudes and motivations, methods and strategies in solving problems. The process evaluation requires students to give a written description of the ideas and plan to complete the project works. Teachers can take it as a breakthrough point in the process evaluation and know about the specific circumstance through giving guidance on the works of team. In this way, teachers can monitor the mutual evaluation between team leaders and team members. The teachers have rights to cancel the improper scores given by team leaders or members. In the guidance and communication, teachers should look at students' progress and development and encourage them to build confidence in completing the project works. In the process evaluation, the teacher do not grade the works of teams and team members, but their effective monitoring can embody the objectivity, development and diversification of evaluation on students and guarantee the smooth development of project teaching.

\section{Self-Evaluation of Students}

Students' self-evaluation means their value judgment on learning and development according to the evaluation goals and standards in learning process. It is an important part of the project teaching. Students carry out self-summary once a week or after completing a project and fill in the form of selfevaluation. It aims at developing students' habits of selfsummary and self-reflection, building students' confidence, highlighting their advantages and frankly exposing the deficiencies, in order to form an ordered and positive learning atmosphere. The self-evaluation can involve students' attitude, values, responsibility, theoretical knowledge, practical operation skills, personal quality and satisfaction on themselves.

\section{E. Evaluation on Teacher's Guidance}

The evaluation on teacher's guidance is also an important part of the evaluation on learning process. The project teaching is an explorative learning style. [4] Because the students "separate from" the teacher for the first time, teacher's guidance plays a crucial role in the smooth implementation of works. Without the guidance of teachers, it may increase students' burden in homework and psychological burden and have negative effects on students, affecting the effects of the project teaching. The guidance and evaluation of teachers mainly include: whether the guidance is timely, whether the teacher keeps the communication with students, whether the teacher has a broad scope of knowledge, and whether the teacher properly coordinates the relations with other disciplines in teaching. The evaluation on teacher's guidance can be carried out for several times in the project teaching of 
each semester. It is implemented by the discipline group of the project teaching.

\section{CONCLUSION}

In a word, the evaluation on project teaching is the activity of value judgment in accordance with certain standard of value. We must follow the evaluation principles of diversification, development and objectivity according to the characteristics of project teaching. The teaching evaluation system must be "comparable, measurable and easy to operate". For the evaluation on effects of the project teaching, we must combine the process evaluation with the outcome evaluation and focus on students' professional ability, method ability and social ability in the project completion, so as to guarantee the smooth implementation of project teaching.

\section{REFERENCES}

[1] Tang Shuling. Research on the Evaluation System of Project Teaching in Higher Vocational Colleges, Adult Education, 2010 (3)

[2] Shi Tiefeng. Exploration on the Project Teaching Model of Computer Professional Course in Higher Vocational Colleges, China Adult Education, 2008 (12)

[3] Li San. Research on the Teaching Model of Student Teamwork [J], Journal of East China Jiaotong University, 2005 (12)

[4] Shao Danping. Discussion on the Evaluation of Student Teamwork in the Project Teaching of Higher Vocational Colleges, Education and Vocation, 2011 (11)

[5] Ding Qi. Application of the Project Teaching in the Training Courses of Computer Basis, Coal Technology, 2010 (3)

[6] Fu Dongqi. The Project Teaching in Authentic Assessment-Take the Postgraduate English Teaching of Minzu University of China, Ethnic Education Study, 2009 (4)

[7] Xu Xian. The Design, Implementation and Evaluation of Project Teaching of Computer Course in the Secondary Vocational School [D], Nanjing Normal University, 2011

[8] Rudolf Pfeifer, Fu Xiaofang. Theory and Practice on the Project Teaching [M], Jiangsu Education Publishing House, 2007

[9] Yang Xiaoli. Research on the Application of Learning Based on the Projects in the Information Technology Class of Junior High Schools [D], Zhejiang Normal University, 2009. 